\title{
Development of an online radiative module for the computation of aerosol optical properties in 3-D atmospheric models: validation during the EUCAARI campaign
}

\author{
B. Aouizerats ${ }^{1}$, O. Thouron ${ }^{1}$, P. Tulet ${ }^{1,2}$, M. Mallet ${ }^{3}$, L. Gomes ${ }^{1}$, and J. S. Henzing ${ }^{4}$ \\ ${ }^{1}$ CNRM/GAME, Meteo-France/CNRS-INSU, URA1357, 42 av G. Coriolis, 31057 Toulouse, France \\ ${ }^{2}$ LACy, Université de La Réunion, 15 av René Cassin, 97715 Saint-Denis, France \\ ${ }^{3}$ LA, Université de Toulouse, 14 av Ed Belin, 31400 Toulouse, France \\ ${ }^{4}$ Netherlands Organisation for Applied Scientific Research, TNO, 80015 Utrecht, The Netherlands
}

Received: 30 April 2010 - Published in Geosci. Model Dev. Discuss.: 1 June 2010

Revised: 7 October 2010 - Accepted: 8 October 2010 - Published: 25 October 2010

\begin{abstract}
Obtaining a good description of aerosol optical properties for a physically and chemically complex evolving aerosol is computationally very expensive at present. The goal of this work is to propose a new numerical module computing the optical properties for complex aerosol particles at low numerical cost so that it can be implemented in atmospheric models. This method aims to compute the optical properties online as a function of a given complex refractive index deduced from the aerosol chemical composition and the size parameters corresponding to the particles.

The construction of look-up tables from the imaginary and the real part of the complex refractive index and size parameters will also be explained. This approach is validated for observations acquired during the EUCAARI (European integrated project on aerosol cloud climate air quality interactions) campaign on the Cabauw tower during May 2008 and its computing cost is also estimated.

These comparisons show that the module manages to reproduce the scattering and absorbing behaviour of the aerosol during most of the fifteen-day period of observation with a very cheap computationally cost.
\end{abstract}

\section{Introduction}

While the greenhouse effect on global warming is quite well understood and leads to a quantification of global temperature increases, the effects of aerosol particles on the radiative budget of the atmosphere are still modelled only roughly

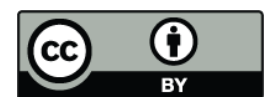

Correspondence to: B. Aouizerats (benjamin.aouizerats@cnrm.meteo.fr)
(Forster et al., 2007). The direct, indirect and semi-direct effects of aerosols may have opposite impacts on the Earth's radiative budget, as noted in the third and fourth reports by the Intergovernmental Panel on Climate Change (IPCC, 2007), and there are still large uncertainties of radiative forcing by anthropogenic aerosols.

Modelling the aerosol particles' size distribution, chemical composition, optical properties, and impacts on radiative forcing is therefore a major objective in the understanding and quantification of the effects of aerosols on the atmosphere radiative budget. Atmospheric research models such as meteorological forecasting models and regional-global climate models, generally use climatology or parametrization of the aerosol optical properties in order to quantify their impacts on radiations (Kinne et al., 2006; Solmon et al., 2008).

Studying aerosols with meso- to fine-scale models may imply high variability of the physical and chemical properties, such as the description of size distributions and chemical compositions of urban polluted aerosols (Costabile et al., 2009; Raut and Chazette, 2008). In such cases, the temporal and spatial variability of aerosol size and chemical description is so high that online coupling with a radiative module is the only way to obtain a good quantification of the aerosol optical properties, radiative direct forcing and feedback. The current methods used to quantify the optical properties are not accurate enough to take the high variability of aerosol composition and size distribution into account.

At those resolutions, it is imperative to consider the ageing of the aerosol and then, the evolution of the size distribution and the chemical composition of the aerosol particles. For example, the absorptivity of primary absorbing carbonaceous particles is due to the coating of carbonaceous aerosols by secondary hydrophilic particles (Jacobson, 2000;

Published by Copernicus Publications on behalf of the European Geosciences Union. 
Mikhailov et al., 2006). In parallel, the increase of the particle size also impacts the scattering and absorbing power of the aerosol (Seinfeld and Pandis, 1997). In that sense, it is necessary to have a good description of both chemical and physical aspects. Modelling the chemical evolution of aerosols and computing the aerosol optical properties as prognostic variables is numerically very expensive. Because of this high cost, which results from an iterative computation of particle optical properties, the computation of aerosol optical properties as a function of its size distribution and chemical composition is never performed within meso-scale atmospheric models nor within weather models. In several models, the impacts of aerosols on radiation is parameterized either by climatology tables or as a function of the main compounds concentration deduced from the literature (Kinne et al., 2006). In Grini et al. (2006), the effect of dust particles on radiation is studied with an evolving aerosol size distributions, but the aerosol is supposed to be only one kind of chemical composition. We propose a more complex approach, with a number of aerosol compounds taken into account higher than in usual methods (Lesins et al., 2002).

In this context, the goal of the present work is to set up a computationally cheap module depending on a complex physical and chemical aerosol description to compute the optical properties at six short wavelengths.

The EUCAARI (European integrated project on aerosol cloud climate air quality interactions) field experiment (Kulmala et al., 2009) which took place during May 2008 near Cabauw (Netherlands) provided us with a complete data set of aerosol measurements for the validation of the work. The Cabauw tower was fully equipped with a set of instruments measuring various aerosol properties. The location of the Cabauw site between the North Sea and the industrialized area of Rotterdam allowed different aerosol types, from polluted to maritime air masses, to be observed.

The first section will describe the bases used to compute the aerosol optical properties, and highlight the sensitivity of those parameters as a function of both physical and chemical aerosol description. Then the building of look-up tables in order to save time during the computation will be explained, and the resulting optical properties will be evaluated in regard of Mie computations. Finally, the comparisons between observations acquired during the EUCAARI campaign at the Cabauw tower and computations from the module will be presented.

\section{Computation of optical parameters}

In order to compute the aerosol optical properties, we applied the Mie theory (Mie, 1908) assuming that the aerosol was made up of spherical particles. Relative to other theories that exist to compute the optical properties of a particle, the Mie theory remains the method that is the most commonly used at present. For a given complex refractive index $k=k_{\mathrm{r}}+i \cdot k_{i}$ and a given effective radius $r$ at a wavelength $\lambda$, the Mie theory computes the extinction, absorption and scattering, efficiency of the particle which are noted $Q_{\text {ext, abs, sca }}(r, \lambda)$, respectively, and the phase function $P(\theta, r, \lambda)$. The asymmetry parameter $g^{\prime}$ can be defined from the phase function as:

$g^{\prime}(r, \lambda)=\frac{1}{2} \int_{0}^{\pi} P(\theta, r, \lambda) \cos (\theta) \sin (\theta) d \theta$

Because of the high cost of the explicit fluxes computation, the radiative models commonly use the following three optical parameters: the extinction coefficient or $b$, the single scattering albedo (ratio of scattering to extinction) or SSA, and the asymmetry parameter for the aerosol population, $g$, by integrating $g^{\prime}$ over the radius. Considering the aerosol size distribution $n(r)$, the optical parameters can be computed for a given radius $r$ as:

$$
\begin{aligned}
& b(\lambda)=\int_{0}^{+\infty} Q_{\mathrm{ext}}(r, \lambda) \pi r^{2} n(r) d r \\
& \operatorname{SSA}(\lambda)=\frac{\int_{0}^{+\infty} Q_{\mathrm{sca}}(r, \lambda) \pi r^{2} n(r) d r}{\int_{0}^{+\infty} Q_{\mathrm{ext}}(r, \lambda) \pi r^{2} n(r) d r} \\
& g(\lambda)=\frac{\int_{0}^{+\infty} r^{2} n(r) Q_{\mathrm{sca}}(r, \lambda) g^{\prime}(r, \lambda) d r}{\int_{0}^{+\infty} r^{2} n(r) Q_{\mathrm{sca}}(r, \lambda) d r}
\end{aligned}
$$

One of the first steps to apply the Mie theory to an aerosol particle with a complex chemical composition, is to define a refractive index for the whole aerosol.

It is important to consider an evolving refractive index for the aerosol. Indeed, the main objective of this study is to perform an online computation of the aerosol optical properties considering an aerosol evolving through its size distribution and its chemical composition. The purpose of this study is to set up a module for a large set of aerosol compositions. As discussed in Chylek et al. (2000), the Maxwell-Garnett mixing rule suits the best for situations with many insoluble particles suspended in solution. Yet, the small scale studies about aerosol particles and with a high spatial variability usually take place in urban areas, which precisely show those conditions.

In order to define a refractive index corresponding to an aerosol particle composed of different chemical components, the Maxwell-Garnett equation (Maxwell-Garnett, 1904) as defined in Tombette et al. (2008) allows us to link the chemical composition of the aerosol to a refractive index and then to take the particle size distribution into account.

\subsection{The Maxwell-Garnet equation}

This approach considers the aerosol as being made up of an inclusion and an extrusion.

The inclusion is composed of the primary and solid parts of the aerosol, whereas the extrusion is composed of the secondary and liquid parts of the aerosol. Then the effective refraction index is: $k_{\text {aer }}=\epsilon^{2}$

with $\epsilon=\epsilon_{2} \frac{\epsilon_{1}+2 \epsilon_{2}+2 f\left(\epsilon_{1}-\epsilon_{2}\right)}{\epsilon_{1}+2 \epsilon_{2}-f\left(\epsilon_{1}-\epsilon_{2}\right)}$ where 
Table 1. Refractive indices used for the main aerosol species at six wavelengths from Krekov (1993) and from Tulet et al. (2008) for dust.

\begin{tabular}{llccccc}
\hline $\begin{array}{l}\text { Specie/ } \\
\text { Wavelength }\end{array}$ & $217.5 \mathrm{~nm}$ & $345 \mathrm{~nm}$ & $550 \mathrm{~nm}$ & $925 \mathrm{~nm}$ & $2.285 \mu \mathrm{m}$ & $3.19 \mu \mathrm{m}$ \\
\hline $\mathrm{BC}$ & $1.80-0.74 i$ & $1.80-0.74 i$ & $1.83-0.74 i$ & $1.88-0.69 \mathrm{i}$ & $1.97-0.68 i$ & $2.10-0.72 i$ \\
$\mathrm{OCp}$ & $1.45-0.001 i$ & $1.45-0.001 \mathrm{i}$ & $1.45-0.001 \mathrm{i}$ & $1.46-0.001 i$ & $1.49-0.001 i$ & $1.42-0.0126 i$ \\
$\mathrm{Du}$ & $1.448-0.00292 i$ & $1.448-0.00292 \mathrm{i}$ & $1.478-0.01897 i$ & $1.4402-0.00116 i$ & $1.41163-0.00106 i$ & $1.41163-0.00106 i$ \\
$\mathrm{H}_{2} \mathrm{O}$ & $1.36-3.60 \mathrm{E}-8 \mathrm{i}$ & $1.34-3.00 \mathrm{E}-9 \mathrm{i}$ & $1.33-1.80 \mathrm{E}-8 i$ & $1.33-5.75 \mathrm{E}-7 i$ & $1.31-1.28 \mathrm{E}-4 i$ & $1.42-2.54 \mathrm{E}-1 i$ \\
$\mathrm{NO}_{3}^{-}$ & $1.53-5.00 \mathrm{E}-3 i$ & $1.53-5.00 \mathrm{E}-3 i$ & $1.53-6.00 \mathrm{E}-3 \mathrm{i}$ & $1.52-1.30 \mathrm{E}-2 i$ & $1.51-1.30 \mathrm{E}-2 \mathrm{i}$ & $1.35-1.00 \mathrm{E}-2 i$ \\
$\mathrm{NH}_{4}^{+}$ & $1.52-5.00 \mathrm{E}-4 i$ & $1.52-5.00 \mathrm{E}-4 i$ & $1.52-5.00 \mathrm{E}-4 \mathrm{i}$ & $1.52-5.00 \mathrm{E}-4 i$ & $1.51-5.00 \mathrm{E}-4 \mathrm{i}$ & $1.35-1.40 \mathrm{E}-2 i$ \\
$\mathrm{SO}_{4}^{2-}$ & $1.52-5.00 \mathrm{E}-4 i$ & $1.52-5.00 \mathrm{E}-4 i$ & $1.52-5.00 \mathrm{E}-4 \mathrm{i}$ & $1.52-5.00 \mathrm{E}-4 i$ & $1.51-5.00 \mathrm{E}-4 \mathrm{i}$ & $1.35-1.40 \mathrm{E}-2 i$ \\
$\mathrm{SOA}$ & $1.45-0.001 i$ & $1.45-0.001 i$ & $1.45-0.001 i$ & $1.46-0.001 i$ & $1.49-0.001 i$ & $1.42-0.0126 i$ \\
\hline
\end{tabular}

- $\epsilon_{i}$ are the complex effective dielectric (square root of the refractive index) constants in which subscripts 1 and 2 stand for the inclusion and the extrusion.

- $f$ is the volumic fraction of inclusion.

In the computation it is assumed that aerosol particles are only composed of primary Organic Carbon (OCp), Black Carbon (BC), dust, nitrates $\left(\mathrm{NO}_{3}^{-}\right)$, sulphates $\left(\mathrm{SO}_{4}^{2-}\right)$, ammonium $\left(\mathrm{NH}_{4}^{+}\right)$, water $\left(\mathrm{H}_{2} \mathrm{O}\right)$ and Secondary Organic Aerosols (SOA).

The inclusion or core of the aerosol is then composed of the OCp, the $\mathrm{BC}$ and the dust whereas the extrusion or shell is composed of $\mathrm{NO}_{3}^{-}, \mathrm{SO}_{4}^{2-}, \mathrm{NH}_{4}^{+}, \mathrm{H}_{2} \mathrm{O}$ and $\mathrm{SOA}$.

The refractive index for each component considered is as defined by Krekov (1993) and Tulet et al. (2008) and shown in Table 1.

\subsection{Sensitivity of optical parameters}

Here, we conducted various sensitivity tests based on variations of the aerosol size distribution (Sect. 2.3.1) and chemical composition (Sect. 2.3.2). Although these results are well known by the radiation community, the goal of this section is to highlight the non-linearity of the aerosol optical properties evolution and the necessity of the proposed parametrization. In order to show the importance of considering a consistent size distribution and chemical composition for the aerosol, Mie computations were performed with different refractive indices and different size distributions.

\subsubsection{Sensitivity to size distribution}

The size distributions were represented by a lognormal function and described by a median radius and a geometric standard deviation. The effective radius, representing the predominant radius with respect to radiation, is expressed as $r_{\mathrm{eff}}=r_{\mathrm{v}}^{3} / r_{\mathrm{s}}^{2}$ with $r_{\mathrm{v}}, r_{\mathrm{s}}$ standing respectively for the volume mean radius and surface mean radius depending on the geometric standard deviation.

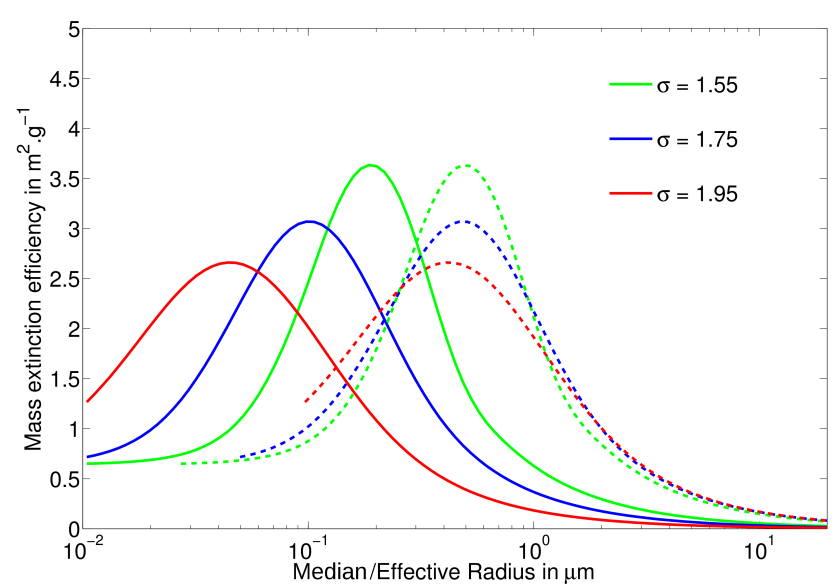

Fig. 1. Mass extinction efficiency as a function of the median radius in solid lines and in function of the effective radius in dashed lines for three geometric standard deviation at the wavelength of $550 \mathrm{~nm}$ and a complex refractive index of 1.55-0.1i.

Figure 1 shows that for a given refractive index of 1.55 $0.1 \mathrm{i}$, the increase of the median radius and the geometric standard deviation has a direct impact on the mass extinction efficiency distribution. For the three geometric standard deviations considered: $1.55,1.75$ and 1.95 , the evolution of the mass extinction efficiency is non-linear with respect to both the median radius and the effective radius, and can show a difference of $40 \%$. The maximum value for each geometric standard deviation considered stands for a different median radius and can reach $3.6 \mathrm{~m}^{2} \mathrm{~g}^{-1}$ for a geometric standard deviation of 1.55 whereas it reaches only $2.5 \mathrm{~m}^{2} \mathrm{~g}^{-1}$ for a geometric standard deviation of 1.95 .

Because aerosol size distributions are usually expressed according to the median radius and also because the nonlinearity of the parameters stand as a function of both effective and median radius, the results will be shown as a function of the median radius in the rest of the study, for ease of understanding. Figure 2 shows the extinction efficiency $Q_{\text {ext }}$, drawn in black and the three size distributions corresponding 


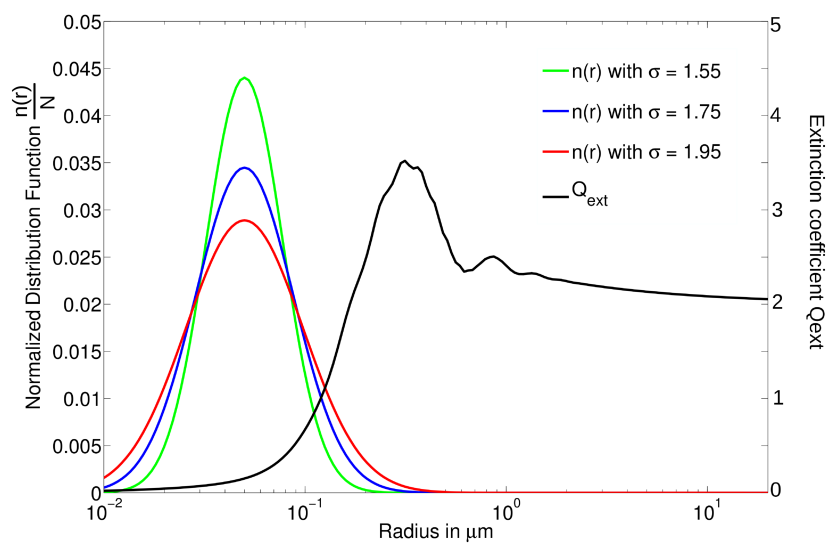

Fig. 2. Extinction efficiency as a function or radius overlaid on the three size distributions corresponding to the same geometric standard deviations as in Fig. 1 and the same median radius of $0.045 \mu \mathrm{m}$ and a refractive index of $1.55-0.1 i$.

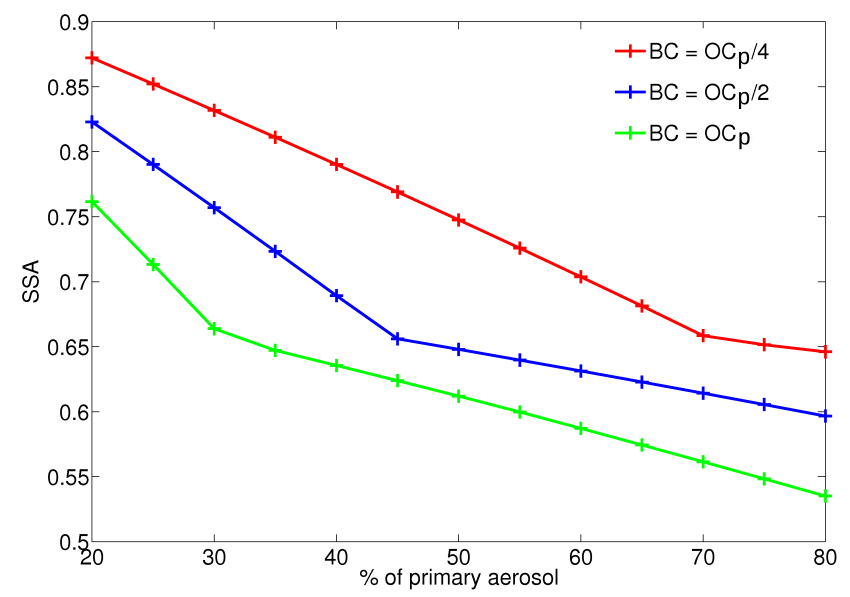

Fig. 3. Single scattering albedo at the $550 \mathrm{~nm}$ wavelength versus percentage of primary aerosol for 3 different core compositions with a median radius of $0.15 \mu \mathrm{m}$ and a geometric standard deviation of 1.65 .

to the same median radius of $0.045 \mu \mathrm{m}$ and the three geometric standard deviation are overlaid in red blue and green. The mass extinction efficiency results from the integration of the extinction efficiency multiplied by the size distribution (and a factor of $\pi r^{2}$ ). Figure 2 shows that the non-linearity of the extinction efficiency versus the median or effective radius mainly comes from the high fluctuations of the extinction efficiency up to $2 \mu \mathrm{m}$.

\subsubsection{Sensitivity to chemical composition}

The influence of the chemical composition of the aerosol is shown in Fig. 3. The aerosol is considered to have a fixed median radius of $0.15 \mu \mathrm{m}$, a fixed geometric standard deviation of 1.6 , and a fixed total mass concentration of $10 \mu \mathrm{g} \mathrm{m}^{-3}$.
We calculated the aerosol SSA for different refractive indices by using the Maxwell-Garnett equation (see Sect. 2.2), considering an aerosol composed of 20 to $80 \%$ of core (primary aerosol), and 80 to $20 \%$ of a shell of secondary species composed with the following mass ratio: $0.75 \mathrm{NH}_{4}^{+}, 1 \mathrm{H}_{2} \mathrm{O}$, $1.35 \mathrm{SO}_{4}^{2-}, 0.9 \mathrm{NO}_{3}^{-}$and $1 \mathrm{SOA}$ to ensure the electroneutrality of the secondary solution.

The resulting SSA is computed for 3 different core compositions depending of the $\mathrm{BC} / \mathrm{OCp}$ ration, and for a core proportion varying from 20 to $80 \%$ of the total aerosol mass in steps of 5\%. For example, an aerosol composed of $20 \%$ primary species with $\mathrm{BC}=0.25 \mathrm{OCp}$ inside the core, gives a SSA computed at $550 \mathrm{~nm}$ of 0.87 whereas for an aerosol composed of $80 \%$ primary species with the same $\mathrm{OCp} / \mathrm{BC}$ ratio, the SSA value at the same wavelength is 0.64 .

It is noteworthy that, for the same primary mass, the core composition is also very important for the computation of the SSA. For a primary mass of $50 \%$, and for as much $\mathrm{BC}$ as OCp, the SSA computed reaches 0.62 whereas, with $\mathrm{BC}=1 / 4$ OCp the SSA value is 0.77 .

This is consistent with our expectations because a low SSA means that the extinction efficiency is mainly caused by absorption, and the SSA has lower values when the black carbon concentration, which is a primary and highly absorbing component, increases.

The same phenomenon is observed at the six wavelengths considered but is not shown here.

\section{Methodology for the building of the look-up tables}

An analytical solution was used, employing a look-up table of aerosol optical properties and a mathematical analytical function approximating the Mie computation.

In order to minimize the number of stored terms, the construction of the look-up tables was adjusted in two different ways described thereafter.

\subsection{Description of the polynomial interpolation method}

The first way to minimize the number of stored terms was by approximating the optical parameters with a double 5th degree polynomial interpolation according to the median radius. Considering the median radius as a stored input parameter would be consistent for no more than a hundred cases as pointed out by Grini et al. (2006). To avoid this constraint, the computation and storage of the fifth degree polynomial coefficients that best fitted the optical parameters evolving according to the median radius was taken. In this way, the input terms of the look-up tables are the complex refractive index and the geometric standard deviation. However, in several cases as shown in Fig. 4, the shape of the Mie resulting parameter evolution was poorly reproduced by the best fitted mono polynomial interpolation. The mean relative errors were around $200 \%$ and showed a difference of $1.5 \mathrm{~m}^{2} \mathrm{~g}^{-1}$ 


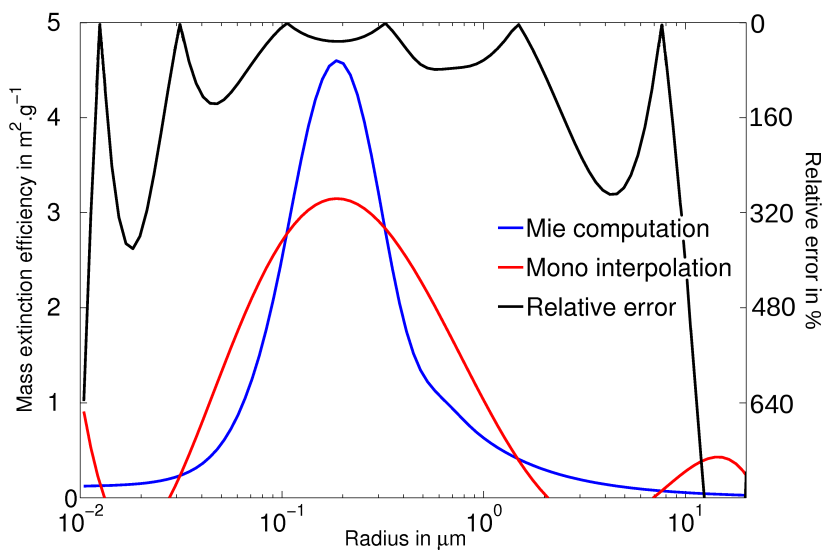

Fig. 4. Mass extinction efficiency (left) at $550 \mathrm{~nm}$ for given values of $\sigma$ and $k_{\mathrm{r}}, k_{i}$ as a function of the radius for the Mie computation versus the mono polynomial interpolation and the relative error (right).

at the maximum of mass extinction efficiency. For this reason the interpolation of the curve was divided into two different curves defined by the evolution from the first radius considered to radius corresponding to the maximum of the curve $r_{\text {cut }}$, and from $r_{\text {cut }}$ to the last radius considered. Then as shown on Fig. 5, for each case considered, the two fifth degree polynomial coefficient and the $r_{\text {cut }}$ were stored. The total number of stored terms was 13 , which is around an eighth of the 100 stored for a discrete radius computation.

To summarize, the polynomial coefficients stored corresponding to the polynomial $P(r)$ follow the equation:

$P(r)=$

$\begin{cases}a_{10}+a_{11} r+a_{12} r^{2}+a_{13} r^{3}+a_{14} r^{4}+a_{15} r^{5} & \text { if } r<r_{\text {cut }} \\ a_{20}+a_{21} r+a_{22} r^{2}+a_{23} r^{3}+a_{24} r^{4}+a_{25} r^{5} & \text { if } r>r_{\text {cut }}\end{cases}$

where $r_{\text {cut }}$ is defined as the median radius corresponding to the maximum value of the optical parameter, and the $12 a_{i, j}$, with $i=1,2, j=0$ to 5 are stored in the look-up table. The coefficients $a_{i, j}$ were computed by a least square approach for the fitting of the two parts of the curve.

\subsection{Range of parameters chosen}

The input terms of the look-up tables are then the imaginary and real part of the complex refractive index of the aerosol, and the geometric standard deviation of the size distribution. The second way to minimize the stored terms was by choosing of input terms in the look-up tables so as to obtain pseudo linearity between adjacent pairs of resulting optical properties.

Tests were performed to select a minimum amount of stored terms (not shown here), and six $k_{i}$, eight $k_{\mathrm{r}}$ and eight $\sigma$ were chosen because of the pseudo linearity between pairs

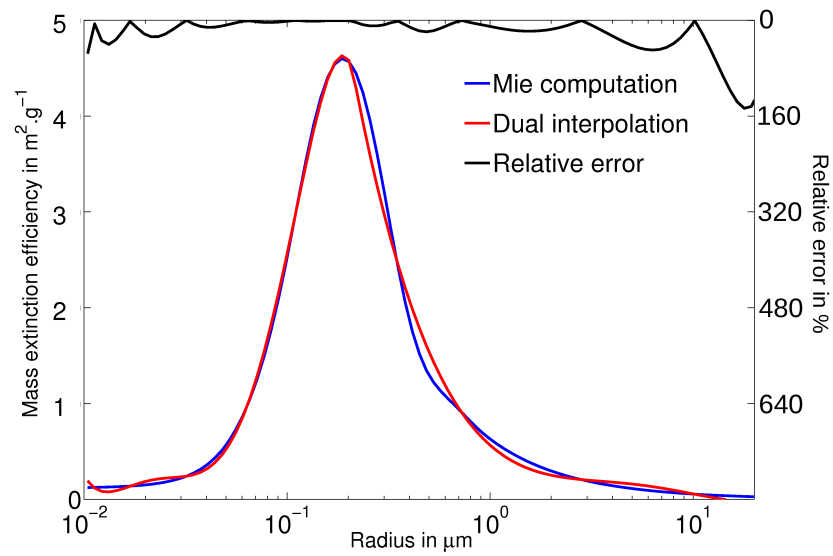

Fig. 5. Mass extinction efficiency (left) at $550 \mathrm{~nm}$ for given values of $\sigma$ and $k_{\mathrm{r}}, k_{i}$ as a function of the radius for the Mie computation versus the dual polynomial interpolation and the relative error (right).

Table 2. Input stored terms into the look-up tables for the polynomial interpolation.

\begin{tabular}{llcc}
\hline$k_{\mathrm{r}}$ & $k_{i}$ & $\sigma$ & $\lambda$ \\
\hline 1.45 & -0.001 & 1.05 & $217.5 \mathrm{~nm}$ \\
1.50 & -0.006 & 1.25 & $345 \mathrm{~nm}$ \\
1.55 & -0.008 & 1.45 & $550 \mathrm{~nm}$ \\
1.60 & -0.02 & 1.65 & $925 \mathrm{~nm}$ \\
1.65 & -0.1 & 1.85 & $2.285 \mu \mathrm{m}$ \\
1.70 & -0.4 & 2.05 & $3.19 \mu \mathrm{m}$ \\
1.75 & $\times$ & 2.25 & $\times$ \\
1.80 & $\times$ & 2.45 & $\times$ \\
\end{tabular}

of terms. This selection method allowed us to interpolate between the results of each optical property corresponding to the two stored values. The stored terms of the input parameters as well as the 6 wavelengths are reproduced in Table 2 . As an example, if the value of the geometric standard deviation is 1.52 , the corresponding aerosol optical properties are the weighted interpolations between the optical properties corresponding to the stored geometric standard deviations of 1.45 and 1.65 .

As in most cases, if we position ourselves between two stored $k_{i}, k_{\mathrm{r}}$ and $\sigma$ we compute the eight polynomials corresponding for the eight different combinations and we interpolate with the appropriate weight for obtaining the weighted optical properties. Although the computation is performed at 6 wavelengths which may be considered as input parameters, there is no possible interpolation between the wavelengths as performed for the other input parameters. 


\subsection{Evaluation of the method in regard of direct Mie computations}

In order to evaluate the dual polynomial interpolation method, a comparison between the resulting and the direct Mie computed aerosol optical properties was performed. This comparison was done at the 6 previously explicited $\lambda$, for 100 considered values of median radii, and for $20 k_{\mathrm{r}}$, $20 k_{i}$ and $18 \sigma$ equally spaced in order not to be located at the stored values, leading to 4320000 comparison points for the 3 optical parameters. Because the computed parameters stands for values of $k_{\mathrm{r}}, k_{i}$ and $\sigma$ which require an interpolation by the module (they do not match to the stored values), this comparison allows to evaluate the module in regard of both polynomial interpolation method and choice of input stored terms.

Figure 6 shows the result of the comparison for the three optical properties between the dual polynomial interpolation module and the direct Mie application. On the top (respectively middle and bottom) is represented the mass extinction efficiency, single scattering albedo and asymmetry parameter, computed by the dual polynomial interpolation as a function of the same parameter computed from the direct Mie application. Due to the very high number of scatter plots (4320000 for each optical parameter), the comparison is shown as a 2-D density function computed over 100 equally splitted bins. For each bin, the 2-D density function is computed as a function of the number of sampling included in the bin. The first coloured contour (dark blue) stands for $99 \%$ of the optical parameters computed by the dual polynomial interpolation included within the area. The 1-D density function of the Mie computed optical parameters are represented by the continuous red lines and shows to which optical parameter values do the most cases stand for. The 1-D density function is computed as a function of the total number of sampling.

First, Fig. 6 shows that for the three optical parameter computations, the dual polynomial interpolation method manages to reproduce the values computed by the direct Mie application. Indeed, almost all of the parameters computed by the module follow the linear curve $x=y$ represented by a continuous black line. The correlation coefficients value standing for the three optical parameters are respectively $0.9992,0.9946$ and 0.9994 . The most large differences stand for extreme cases with very low median radius or very high geometric standard deviation. As an example, the highest values of mass extinction efficiencies which can reach more than $15 \mathrm{~g} \mathrm{~m}^{-2}$ stand for very unusual combinations of parameters such as a geometric standard deviation below 1.4, a real part of the refractive index of 1.80. These extreme cases all occur on the first wavelength. We can also notice that for the single scattering albedo, the highest dispersion stand for very low values, meaning that the extinction is mainly absorbing. Moreover, the most computed cases, represented by the continuous red line, occur where the density function is
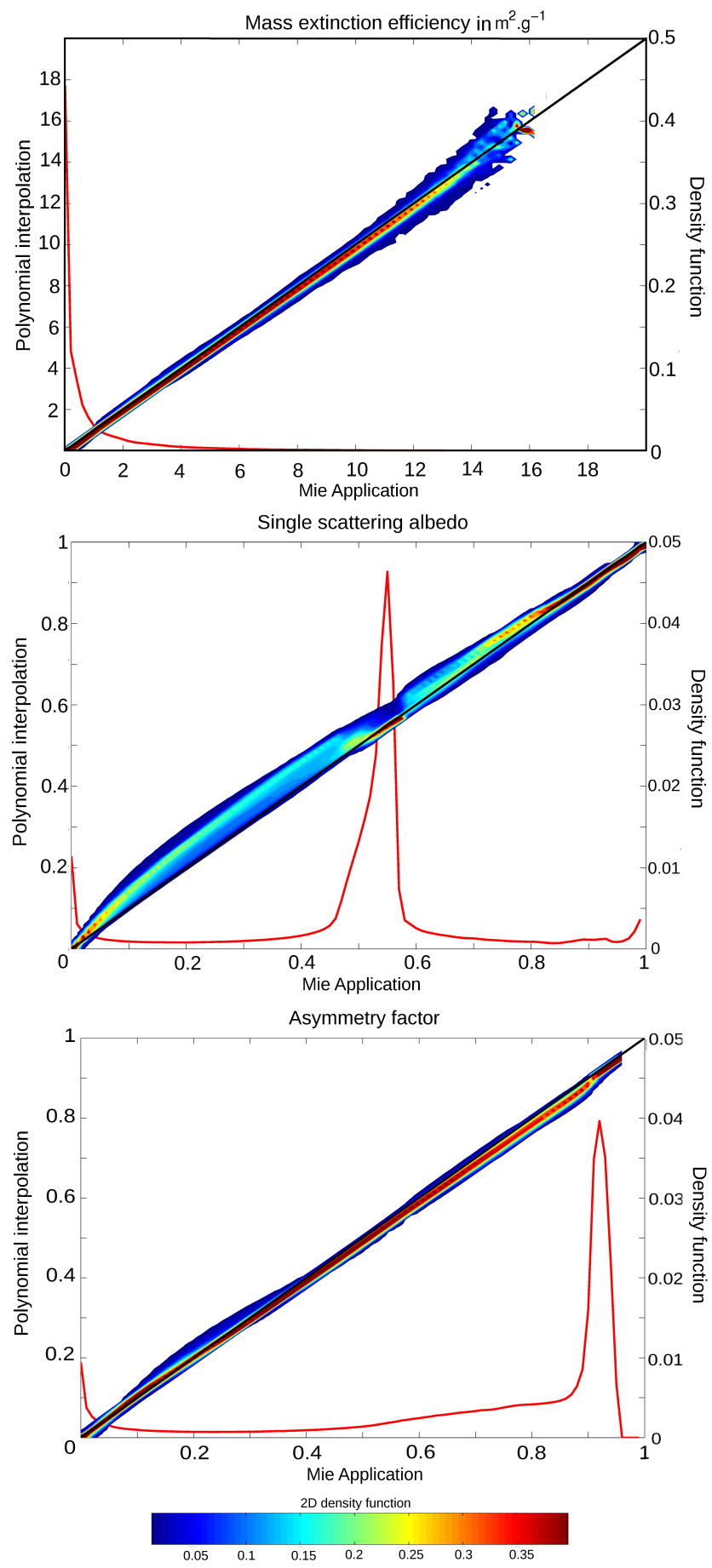

Fig. 6. Comparison of the optical properties (mass extinction efficiency, single scattering albedo and asymmetry parameter) computed by the dual interpolation method (y-axis) and the direct Mie application (x-axis) represented by the 2-D density function in color. Overlaid is the 1-D density function (right scale, continuous red line) of the Mie computed parameters, and the continuous black line represents $\mathrm{x}=\mathrm{y}$ regression. 
the highest, and at this points there is a good linearity between the two methods.

\section{Validation during the EUCAARI campaign}

For the validation of the module, a full set of measured data for the inputs and of the outputs was required. Concerning inputs, a description of the aerosol size distribution giving the median radius and the geometric standard deviation for each mode, associated with the aerosol chemistry giving the aerosol composition was needed. Concerning outputs, the measurements of the aerosol optical properties was also necessary.

During the EUCAARI field experiment, a complete set of instruments were available at the Cabauw tower. Between 15 and 29 May 2008, all the selected instruments requested to test this module were operational.

\subsection{Description of observations}

\subsubsection{Period and instruments}

The data were processed to give one average value over 30 min for each parameter during the 15 days.

- The aerosol size distribution was deduced after merging the size spectral observations from a SMPS (model TSI 3034) and an APS (model TSI 3321): the SMPS measures the aerosol size distribution between 10 and $500 \mathrm{~nm}$, and the APS between $500 \mathrm{~nm}$ and $20 \mu \mathrm{m}$. All the measurements were made in dry conditions $(\mathrm{RH}<50 \%)$.

Then, a lognormal fit that best approached the observed distribution was found. At each time step, a least square approach gave the median radius, the geometric standard deviation and the mass concentration for each aerosol mode observed by both instruments. To link the number of aerosol directly measured to the mass of aerosol, the assumption of spherical particles with a density of $2.5 \mathrm{~g} \mathrm{~cm}^{-3}$ was done.

- The chemical composition of the aerosol was deduced from the observations of an aerosol mass spectrometer (AMS, cTOF type) and a multi angle absorption photometer (MAAP model 5012). The AMS gave us the mass concentration of particulate organic matter (POM), $\mathrm{NO}_{3}^{-}, \mathrm{NH}_{4}^{+}, \mathrm{SO}_{4}^{2-}$ at each time step and the black carbon (BC) concentration was deduced form the MAAP measurements. The water concentration was deduced from the thermodynamical equilibrium EQSAM (Metzger et al., 2002) on dry conditions.

- The scattering coefficient at $550 \mathrm{~nm}$ was measured by a nephelometer (model TSI 3563). A truncation correction is performed on the nephelometer data according to Mallet et al. (2009). The absorption coefficient was measured by the MAAP at $670 \mathrm{~nm}$ and deduced at $550 \mathrm{~nm}$ by using the absorption Angström coefficient measured with an aethalometer. All these measurements were also made in dry conditions.

A summary of the instruments and the associated aerosol properties is presented in Table 3 .

\subsubsection{Methodology and assumptions}

Figure 7 shows as a diagram the methodology used for the validation of the radiative module. Some assumptions were made from the observations. The choice was to split the POM between primary organic carbon and secondary organic carbon with a 60-40\% distribution according to Dentener et al. (2006). A second assumption was to split the aerosol compounds equally between modes. The SMPS+APS observations are fitted to describe the aerosol mass size distribution along three lognormal modes: $M_{i}, \sigma_{i}, r_{i}$ with $i$ for the mode index. This fit is performed according to two assumptions allowing to compute the mass concentration from the observed number concentration: the aerosol is supposed to be spherical and has a constant density $\rho$. From this fit is also deduced the total aerosol mass concentration $M_{s d}$ and the aerosol mass concentration integrated from 0.01 to $0.5 \mu \mathrm{m}\left(M_{s d, 500}\right)$. The particle organic matter, ammonium, nitrate, sulfate, and black carbon mass concentration are deduced from the AMS+MAAP observations (respectively $M_{\mathrm{POM}}, M_{\mathrm{NH}_{4}}, M_{\mathrm{SO}_{4}}, M_{\mathrm{NO}_{3}}$, $\left.M_{\mathrm{BC}}\right)$. It was noticed that the AMS had a cut-off diameter of $500 \mathrm{~nm}$. The total aerosol mass concentration for aerosols with a diameter inferior to $500 \mathrm{~nm}$ and as observed by the AMS+MAAP is also computed $\left(M_{c h, 500}\right)$. Then, for each of the three considered mode, the mass concentration of each aerosol compounds is computed and weighted by the total mass concentration observed by the SMPS+APS $\left(M_{\mathrm{POM}, \mathrm{i}}\right.$, $\left.M_{\mathrm{NH}_{4}, i}, M_{\mathrm{SO}_{4}, i}, M_{\mathrm{NO}_{3}, i}, M_{\mathrm{BC}, \mathrm{i}}\right)$. The inputs for the radiative module are then for each mode: $M_{\mathrm{POM}, \mathrm{i}}, M_{\mathrm{NH}_{4}, i}, M_{\mathrm{SO}_{4}, i}$, $M_{\mathrm{NO}_{3}, i}, M_{\mathrm{BC}, i}, r_{i}, \sigma_{i}$. The outputs are then for each of the $i$-th mode: the extinction coefficient $b_{\text {ext }, i}$, the single scattering albedo $\mathrm{SSA}_{i}$, and the asymmetry parameter $g_{i}$. The aerosol optical properties are then computed for the total aerosol population: the mass extinction efficiency $\mathrm{MEE}_{\bmod }$ and the single scattering albedo $\mathrm{SSA}_{\text {mod. }}$ These parameter are evaluated regarding the observations. The absorption coefficient is measured by the MAAP at the wavelength of $670 \mathrm{~nm}\left(b_{\text {abs,obs, } 670}\right)$. The value of the absorption coefficient at the wavelength of $550 \mathrm{~nm}\left(b_{\mathrm{abs}, \mathrm{obs}, 550)}\right)$ is deduced from the multiplication by the absorption Angström coefficient $\left(\mathrm{AAE}_{\mathrm{obs}}\right)$ measured by an aethalometer. Finally, the scattering coefficient is measured by the nephelometer at the wavelength of $550 \mathrm{~nm}\left(b_{\text {sca,obs, } 550) \text {. The mass extinction }}\right.$ efficiency and the single scattering albedo are then computed $\left(\mathrm{MEE}_{\mathrm{obs}}, \mathrm{SSA}_{\mathrm{obs}}\right)$ and compared to the module's outputs. 


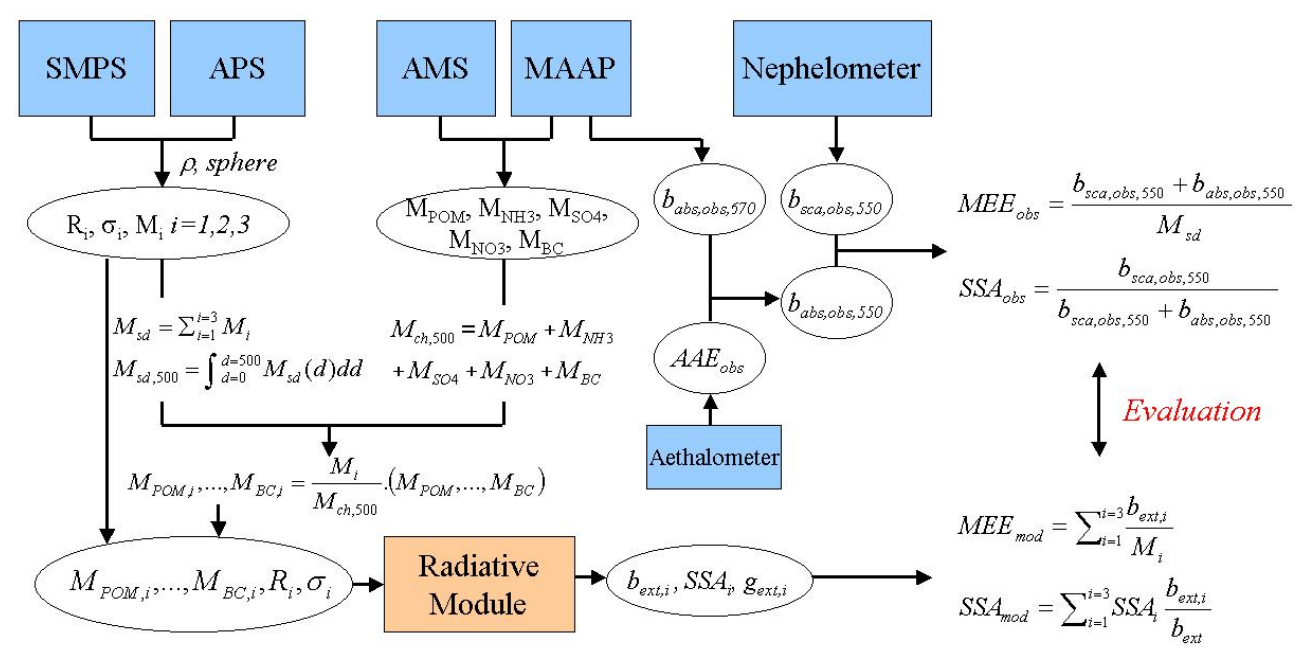

Fig. 7. Diagram representation of the methodology used for the validation. $\rho$ is the density considered for the aerosol particle. $i$ is the index of the aerosol lognormal mode. $M_{i}$ is the aerosol mass concentration value for the $i$-th mode obtained from the lognormal fit adjusted on the SMPS+APS size distribution observations. $M_{s d}$ is the total mass concentration deduced from the fit of the SMPS+APS size distribution observations. $M_{S d, 500}$ is the mass concentration calculated from the fit of the SMPS+APS size distribution observations integrated up to $500 \mathrm{~nm}$. $M_{\mathrm{POM}}, M_{\mathrm{NH}_{4}}, M_{\mathrm{SO}_{4}}, M_{\mathrm{NO}_{3}}$, is the particle organic matter, ammonium, sulfate, nitrate mass concentration respectively measured by the AMS. $M_{\mathrm{BC}}$ is the black carbon mass concentration deduced from the MAAP. $M_{c h, 500}$ is the mass concentration deduced from the AMS+MAAP observations up to $500 \mathrm{~nm}$. $b_{\text {abs,obs, } 670}$ is the absorption coefficient measured by the MAAP at the wavelength of $670 \mathrm{~nm}$. $\mathrm{AAE}_{\mathrm{abs}, \mathrm{obs}}$ is the absorption Angström coefficient measured by the aethalometer. MEE is th Mass extinction efficiency.

Table 3. Summary of aerosol measurements on Cabauw tower during the EUCAARI campaign.

\begin{tabular}{lccc}
\hline & Size distribution & chemistry & optical properties \\
\hline SMPS & $D_{i}, \sigma_{i} M_{i}$ & $\times$ & $\times$ \\
APS & $D_{i}, \sigma_{i} M_{i}$ & $\times$ & $\times$ \\
AMS & $\times$ & $M_{\mathrm{POM}}, M_{\mathrm{NO}_{3}^{-}}, M_{\mathrm{SO}_{4}^{2-}}, M_{\mathrm{NH}_{4}^{+}}$ & $\times$ \\
MAAP & $\times$ & $M_{\mathrm{BC}}$ & $b_{\mathrm{abs}}$ \\
Aethalolometer & $\times$ & $\times$ & $\mathrm{AAE}$ \\
Nephelometer & $\times$ & $\times$ & $b_{\text {scat }}$ \\
\hline
\end{tabular}

\subsubsection{First results from instruments}

The 15-day period of the study showed different aerosol concentration level due to different regimes. As presented in Fig. 8, the aerosol composition gives us several items of information: from 15 to 17 May, the aerosol shows a continental composition; from 17 to 21 May, the low level of aerosols is characteristic of a scavenging period with a clean air mass and fresh aerosols; from 21 to 29 May, the aerosol comes again from a continental air flux and the secondary fraction of the aerosol, in particular the inorganic species, also grows in proportion. The total measured mass concentration is also represented in Fig. 8 as a black line. Also one can note that the ratio of primary aerosol to secondary aerosol remains quite stable during the fourteen days of measurements.

Figure 9 shows the evolution of the aerosol size distribution during the fourteen days of measurement. This figure is the result of the fit applied to the SMPS+APS data and used as inputs in the module.

The Fig. 9 shows the evolution of all the size distribution parameters versus time. The maximum of mass also evolves consequently as already shown in Fig. 8. Finally, the combination of data measuring size description and chemical composition gives a good representation of the period.

It is also noticeable that the absorption Angström exponents observed by the aethalometer show values between 1.21 and 1.27 with a mean of 1.24 . These values show a relatively limited dispersion, and according to bibliography (Russel et al., 2010) are in the same range than continental and urban aerosols. 


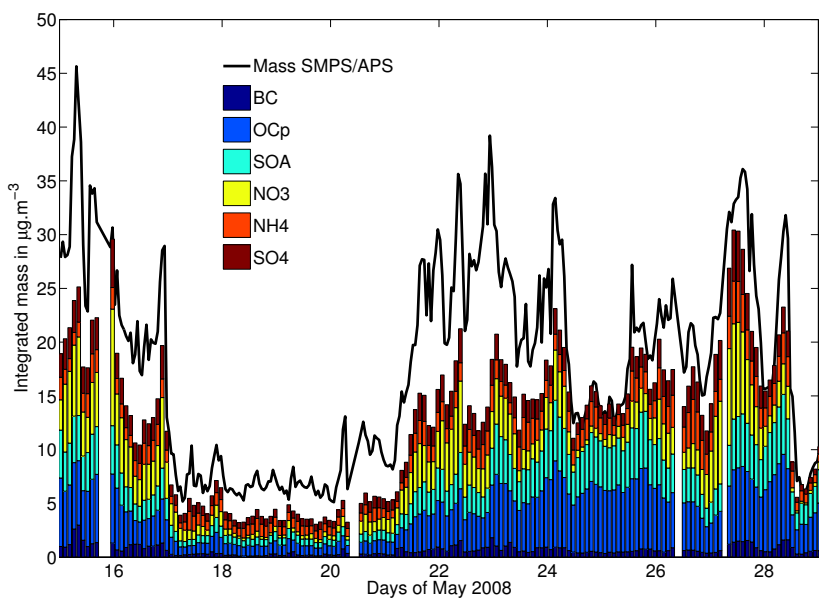

Fig. 8. Evolution of aerosol chemical composition from AMS+MAAP and mass integrated from the SMPS and APS in $\mu \mathrm{g} \mathrm{m}^{-3}$ during the fourteen days of measurement.

\subsection{Comparison of computed optical properties and observations}

Figure 10 shows the single scattering albedo at $550 \mathrm{~nm}$ as calculated form the nephelometer and the MAAP measurements (continuous red line) and computed by the module (dashed blue line).

Figure 11 shows the mass extinction efficiency at $550 \mathrm{~nm}$ as calculated from observations (continuous red line) and computed by the module (dashed blue line). There were no instruments able to measure the asymmetry parameter during the EUCAARI campaign. Therefore, there is no comparison possible with the computed values.

First, the main trend shows that both mass extinction efficiency and single scattering albedo are correctly reproduced by the module during the 15 days. The correlation coefficient for the 15-day period and for the mass extinction efficiency is 0.94 , and 0.89 for the single scattering albedo and the associated biases are 0.32 and 0.0025 , respectively.

Concerning the single scattering albedo, the module mainly manages to reproduce the highest as the lowest values observed, even with high temporal variability. Single scattering albedo values observed and modelled in dry conditions fluctuate around 0.8 (with a mean value of 0.815 for the modelled values and 0.818 for the observed values during the period studied). However, some isolated measurements show low values of single scattering albedo below 0.7. Although such very low values could be unusual, recent studies (Marley et al., 2009; Gomes et al., 2008; Babu et al., 2002; Singh et al., 2005; Ganguly et al., 2006) show single scattering albedo observations showing chronic very low values below 0.6 indicating an higher concentration of absorbing aerosols. In addition, it has to be noted that the SSA observed and modelled are both under dry conditions, leading to lower SSA values compared to wet conditions.

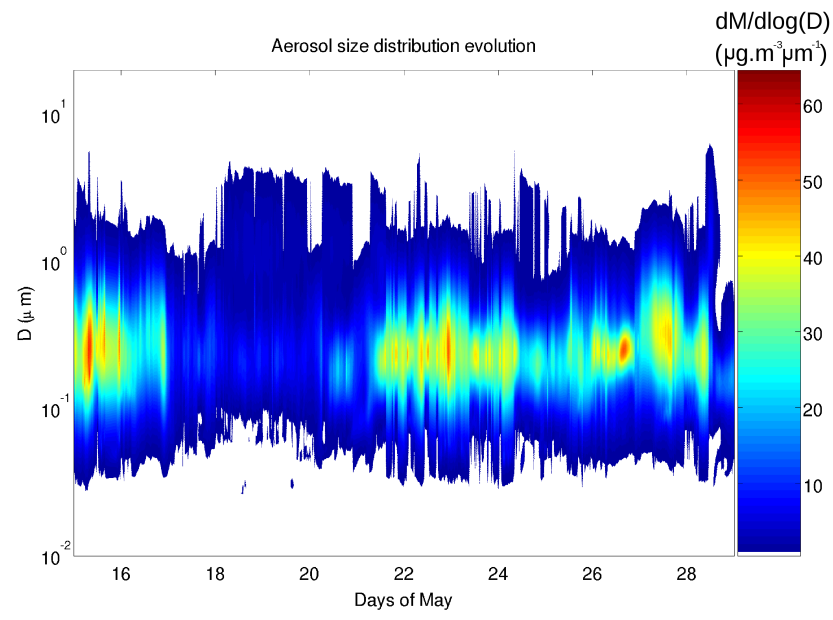

Fig. 9. Evolution of aerosol size distribution fits obtained from SMPS+APS during the fourteen days of measurement.

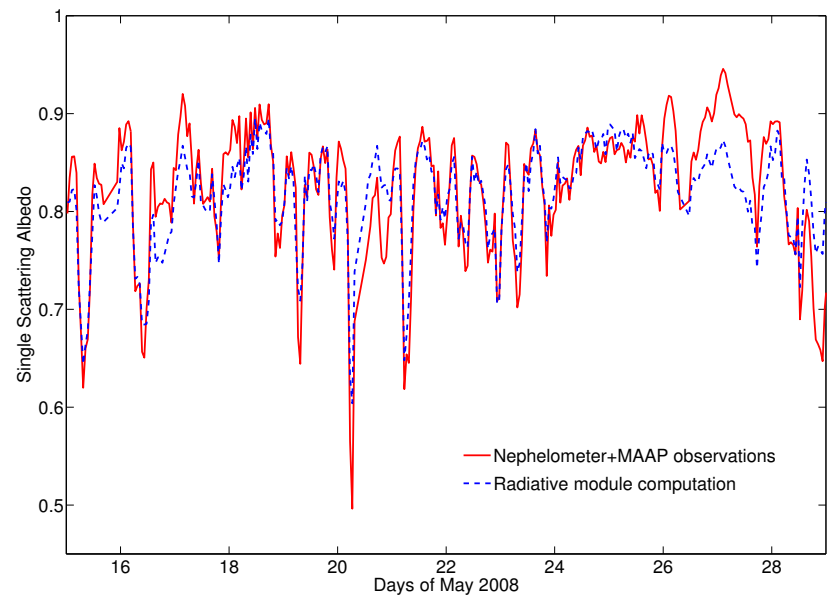

Fig. 10. Evolution of the dry single scattering albedo at $550 \mathrm{~nm}$ measured at Cabauw during EUCAARI by the nephelometer and the MAAP, and computed by the module.

Concerning the mass extinction efficiency comparison, again there is a good agreement between the observations and the computations. However, it is noticeable that from 20 to 24 May, the computations overestimate the mass extinction efficiency by 10 to $80 \%$. To understand why there is a less good correlation especially between 20 and 24 May, Fig. 12 shows the evolution of the difference between the observed and computed mass extinction efficiency (in red) during the 15-day period, and the evolution of the relative error on the integrated mass up to $500 \mathrm{~nm}$ observed by the SMPS+APS $M_{s d, 500}$ and by the AMS+MAAP $M_{c h, 500}$.

The discrepancy between observed and computed mass extinction efficiency between 20 and 24 May, may be directly linked to a major difference of masses calculated from by the two different experimental systems, the SMPS+APS for the aerosol size distribution and AMS+MAAP for the aerosol 


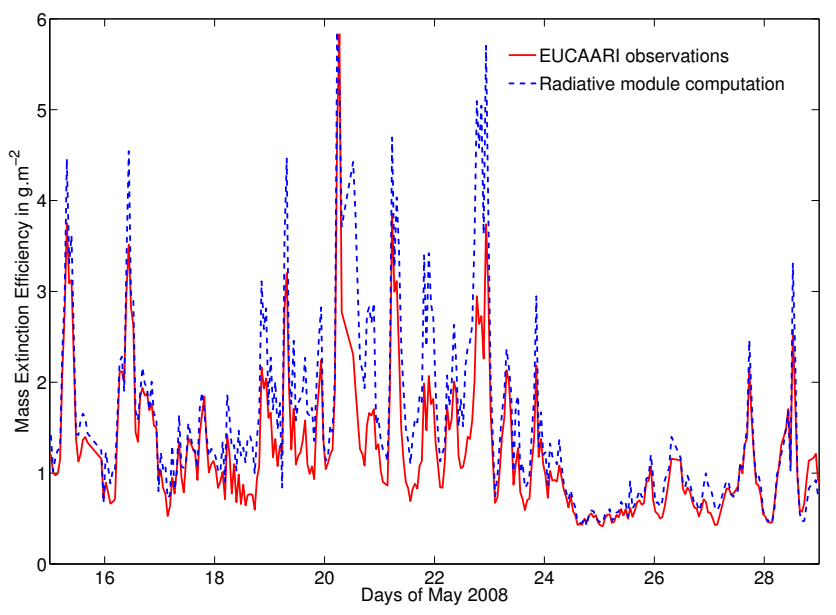

Fig. 11. Evolution of the dry mass extinction efficiency in $\mathrm{g} \mathrm{m}^{-2}$ at $550 \mathrm{~nm}$ measured at Cabauw during EUCAARI and computed by the module.

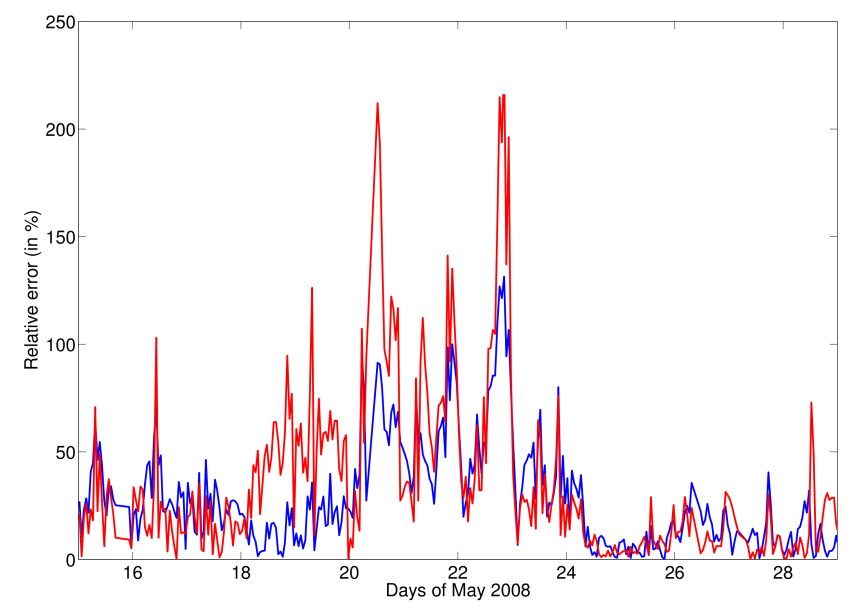

Fig. 12. Relative error between the mass concentration measured by the AMS+MAAP and that deduced from the SMPS+APS for particles up to $500 \mathrm{~nm}$ (blue line) and difference between mass extinction efficiency observed and computed (red line).

chemical composition. Between 20 and 24 May, the relative error between both systems on the aerosol integrated mass up to $500 \mathrm{~nm}$ can reach more than $100 \%$ and the major differences between the observed and computed mass extinction efficiency occur at these same maxima. Thus, the main differences observed may probably come from a discrepancy in the instruments in term of mass measurement, leading to an inconsistency between the inputs and outputs of the module. Moreover, the constant density used for the computations of the module's inputs certainly leads to the main limitation of this evaluation.

\section{Conclusions}

In order to quantify the direct and semi-direct effect of aerosols, it is necessary to compute the aerosol optical properties in atmospheric models depending on an evolving and complex aerosol particle. To study the aerosol particles interaction with radiation in highly temporal and spatial variable locations, such as urban areas, it is necessary to consider a large number of chemical species.

Nevertheless, the high computing cost of the classically applied Mie theory generally leads to a climatological parametrization of aerosol optical properties in regionalclimate models.

The numerical computation was performed for six wavelengths using a vectorial computer (NEC SX8 type), in order to compare the time cost of this module with the other atmospheric processes (turbulence, advection, chemistry, aerosol solver, etc.).

The comparison was made between two standard simulations, with and without computation of the aerosol optical properties. The standard simulation required a cpu time per point per time-step of $98.0 \mu$ s versus the standard simulation with the aerosol optical properties computation has a cpu time per point per time-step of $99.7 \mu$ s. These results show that the numerical cost of the module was no more than $1.7 \%$ of the standard simulation total cost. As an example, the chemistry solving cost of these same simulations is $35.6 \%$.

We can then consider that the previously described module is numerically very cheap relative to other processes and is consequently affordable for most atmospheric modelling.

This work presents a new, computationally cheap module dedicated to the online computation of optical properties according to the particle chemical composition and size distribution.

To minimize the computing cost, the module is founded on look-up tables built by a dual fifth degree polynomial interpolation of the parameters depending on the median radius of the aerosol size distribution. The parameters are the geometric standard deviation of the lognormal size distribution of the aerosol mode considered, and the imaginary and real part of the complex aerosol refractive index corresponding to a chemical composition deduced from the Maxwell-Garnett equation.

The module was then evaluated by using observations acquired during the EUCAARI campaign (May 2008). The numerical cost was also tested.

The comparisons between optical properties modelled by the module and those acquired at the Cabauw tower during fifteen days of measurements shows a good correlation. Furthermore, the numerical cost of the module is shown to be very low, allowing its implementation in atmospheric models treating aerosol size distribution and chemical composition. This optical module is already coupled with the ORILAM aerosol scheme (Tulet et al., 2005, 2006) implemented into the atmospheric research model Meso-NH (Lafore et al., 
1998). This development will be used in future works to investigate feedbacks of polluted aerosols on radiation and urban climate (especially impacts on radiative heating, development of the urban boundary layer and the urban breeze). Such a model could also be used for studying the effect of urban aerosols on UV radiation and the possible feedbacks on atmospheric photochemistry (such as the ozone production) in urban zones.

\section{Supplement related to this article is available online at: http://www.geosci-model-dev.net/3/553/2010/ gmd-3-553-2010-supplement.zip.}

Acknowledgements. This work has been partially funded by European Commission 6th Framework program project EUCAARI, contract no. 036833-2 (EUCAARI), and by the French National Research Agency (ANR) under the AEROCLOUD program, contract no. 06-BLAN-0209. Astrid Kiendler-Scharr from Research Center Juelich, Germany, is acknowledged for providing AMS data. The Meso-NH team is also acknowledged for its support. The topical editor O. Boucher is also acknowledged for his constructive remarks improving this manuscript.

O. Boucher

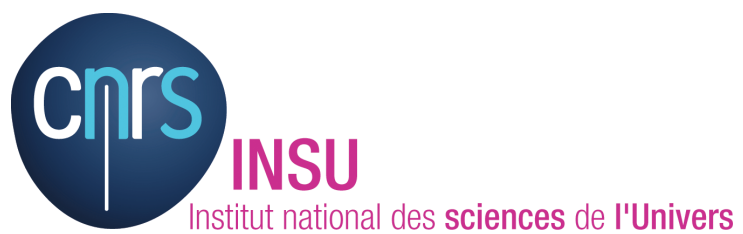

The publication of this article is financed by CNRS-INSU.

\section{References}

Babu, SS., Satheesh, S.K., and Moorthy, K.K.: Aerosol radiative forcing due to enhanced black carbon at an urban site in India, J. Geophys. Res., 29, 1880, doi:10.1029/2002GL015826, 2006.

Chylek, P., Videen, G., Geldart, W., Dobbie, S., and Tso, W.: Effective medium approximation for heterogeneous particles, in: Light Scattering by Nonspherical Particles: Theory, Meas. Geophys. Appl., 273-308, 2000.

Costabile, F., Birmili, W., Klose, S., Tuch, T., Wehner, B., Wiedensohler, A., Franck, U., König, K., and Sonntag, A.: Spatiotemporal variability and principal components of the particle number size distribution in an urban atmosphere, Atmos. Chem. Phys., 9, 3163-3195, doi:10.5194/acp-9-3163-2009, 2009.

Dentener, F., Kinne, S., Bond, T., Boucher, O., Cofala, J., Generoso, S., Ginoux, P., Gong, S., Hoelzemann, J.J., Ito, A., Marelli, L., Penner, J.E., Putaud, J.P., Textor, C., Schulz, M., van der Werf, G.R., and Wilson, J.: Emissions of primary aerosol and precursor gases in the years 2000 and 1750 prescribed data-sets for AeroCom, Atmos. Chem. Phys., 6, 4321-4344, doi:10.5194/acp-6-4321-2006, 2006.

Forster, P., Ramaswamy, V., Artaxo, P., Berntsen, T., Betts, R., Fahey, D., Haywood, J., Lean, J., Lowe, D., Myrhe, G., Nganga, J., Prinn, R., Raga, G., Schulz, M., and van Dorland, R.: Changes in atmospheric constituents and in radiative forcing, in: Climate Change 2007: The Physical Science Basis, Contribution of working group I to the fourth assessment report of the intergovernmental panel on climate change, edited by: Solomon, S., Qin, D., Manning, M., Chen, Z., Marquis, M., Averyt, K. B., Tignor, M., and Miller, H. L., Cambridge University Press, 2007.

Ganguly, D., Jayaraman, A., Rajesh, T.A., and Gadhavi, H.: DWintertime aerosol properties during foggy and nonfoggy days over urban center Delhi and their implications for shortwave radiative forcing, J. Geophys. Res., 111, D15217, doi:10.1029/2005JD007029, 2006.

Gomes, L., Mallet, M., Roger, J.C., and Dubuisson, P.: Effects of the physical and optical properties of urban aerosols measured during the CAPITOUL summer campaign on the local direct radiative forcing, Meteorol. Atmos. Phys., 108, 289-306, 2008.

Grini, A., Tulet, P., and Gomes, L.: Dusty weather forecast using the MesoNH atmospheric model., J. Geophys. Res., 111, D19205, doi:10.1029/2005JD007007, 2006.

IPCC (Ed.): Climate change 2007: The scientific basis. Contribution of working group I to the Fourth Assessment Report of the Intergovernmental Panel on Climate Change, http://www.ipcc. ch/, last access: 27 May 2010, 2007.

Jacobson, M.: A physically-based treatment of elemental carbon optics: Implications for global direct forcing of aerosols, Geophys. Res. Lett., 27, 217-220, 2000.

Kinne, S., Schulz, M., Textor, C., Guibert, S., Balkanski, Y., Bauer, S. E., Berntsen, T., Berglen, T. F., Boucher, O., Chin, M., Collins, W., Dentener, F., Diehl, T., Easter, R., Feichter, J., Fillmore, D., Ghan, S., Ginoux, P., Gong, S., Grini, A., Hendricks, J., Herzog, M., Horowitz, L., Isaksen, I., Iversen, T., Kirkevåg, A., Kloster, S., Koch, D., Kristjansson, J. E., Krol, M., Lauer, A., Lamarque, J. F., Lesins, G., Liu, X., Lohmann, U., Montanaro, V., Myhre, G., Penner, J., Pitari, G., Reddy, S., Seland, O., Stier, P., Takemura, T., and Tie, X.: An AeroCom initial assessment - optical properties in aerosol component modules of global models, Atmos. Chem. Phys., 6, 1815-1834, doi:10.5194/acp-6-1815-2006, 2006.

Krekov, M.: Aerosols Effects on Climate, Univerity of Arizona Press, USA, 9-72, 1993.

Kulmala, M., Asmi, A., Lappalainen, H. K., Carslaw, K. S., Pöschl, U., Baltensperger, U., Hov, Ø., Brenquier, J.-L., Pandis, S. N., Facchini, M. C., Hansson, H.-C., Wiedensohler, A., and O'Dowd, C. D.: Introduction: European Integrated Project on Aerosol Cloud Climate and Air Quality interactions (EUCAARI) - integrating aerosol research from nano to global scales, Atmos. Chem. Phys., 9, 2825-2841, doi:10.5194/acp-92825-2009, 2009.

Lafore, J. P., Stein, J., Asencio, N., Bougeault, P., Ducrocq, V., Duron, J., Fischer, C., Héreil, P., Mascart, P., Masson, V., Pinty, J. P., Redelsperger, J. L., Richard, E., and Vilà-Guerau de Arellano, J.: The Meso-NH Atmospheric Simulation System. Part I: adiabatic formulation and control simulations, Ann. Geophys., 16, 90-109, doi:10.1007/s00585-997-0090-6, 1998.

Lesins, G., Chylek, P., and Lohmann, U.: A study of internal and external mixing scenarios and its effect on aerosol optical properties and direct radiative forcing, J. Geophys. Res., 107(D10), 4094, doi:10.1029/2001JD000973, 2002.

Mallet, M., Van Dingenen, R., Roger, J.C., Despiau, S., and Cachier, H.: In situ airborne measurements of aerosol optical 
properties during photochemical pollution events, J. Geophys. Res., 110, D03205, doi:10.1029/2004JD005139, 2005.

Marley, N.A., Gaffney, J.S., Castro, T., Salcido, A., and Frederick, J.:Measurements of aerosol absorption and scattering in the Mexico City Metropolitan Area during the MILAGRO field campaign: a comparison of results from the T0 and T1 sites, Atmos. Chem. Phys., 9, 186-206, doi:10.5194/acp-9-186-2009, 2009.

Maxwell-Garnett, J.: Colours in metal glasses and in metallic films, Philos. T. Roy. Soc. A, 203, 385-420, 1904.

Metzger, S., Dentener, F., Pandis, S., and Lelieveld, J.: Gas/aerosol partitioning: 1. A computationally efficient model, J. Geophys. Res., 107(D16), 4312, doi:10.1029/2002GL014769, 2002.

Mie, G.: Beiträge zur Optik trüber Medien, speziell kolloidaler Metallösungen, Ann. Phys.-Leipzig, 330, 377-445, 1908.

Mikhailov, E. F., Vlasenko, S. S., Podgorny, I. A., Ramanathan, V., and Corrigan, C. E.: Optical properties of soot water drop agglomerates: An experimental study, J. Geophys. Res., 111, 1815-1834, doi:10.1029/2005JD006389, 2006.

Raut, J.-C. and Chazette, P.: Vertical profiles of urban aerosol complex refractive index in the frame of ESQUIF airborne measurements, Atmos. Chem. Phys., 8, 901-919, doi:10.5194/acp8-901-2008, 2008.

Russell, P. B., Bergstrom, R. W., Shinozuka, Y., Clarke, A. D., DeCarlo, P. F., Jimenez, J. L., Livingston, J.M., Redemann, J., Dubovik, O., and Strawa, A.: Absorption Angstrom Exponent in AERONET and related data as an indicator of aerosol composition, Atmos. Chem. Phys., 10, 1155-1169, 2010, http://www.atmos-chem-phys.net/10/1155/2010/.

Seinfeld, J. and Pandis, S.: Atmospheric Chemistry and Physics, Wiley Interscience Pub., New York, USA, 691-711, 1997.
Singh, S., Nath, S., Kohli, R., and Singh, R.: Aerosols over Delhi during pre-monsoon months: Characteristics and effects on surface radiation forcing, Geophys. Res. Lett., 32, L13808, doi:10.1029/2005GL023062, 2005

Solmon, F., Chuang, P., Meskhidze, N., and Chen, Y.: Acidic processing of mineral dust iron by anthropogenic compounds over the North Pacific Ocean, J. Geophys. Res., 114, D02305, doi:10.1029/2008JD010417, 2008.

Tombette, M., Chazette, P., Sportisse, B., and Roustan, Y.: Simulation of aerosol optical properties over Europe with a 3-D sizeresolved aerosol model: comparisons with AERONET data, Atmos. Chem. Phys., 8, 7115-7132, doi:10.5194/acp-8-7115-2008, 2008.

Tulet, P., Crassier, V., Cousin, F., Shure, K., and Rosset, R.: ORILAM, a three moment lognormal aerosol scheme for mesoscale atmospheric model. On-line coupling into the MesoNH-C model and validation on the ESCOMPTE campaign, J. Geophys. Res., 110, D18201, doi:10.1029/2004JD005716, 2005.

Tulet, P., Grini, A., Griffin, R., and Petitcol, S.: ORILAM-SOA: a computationally efficient model for predicting secondary organic aerosols in 3D atmospheric models., J. Geophys. Res., 111, D23208, doi:10.1029/2006JD007152, 2006.

Tulet, P., Mallet, M., Pont, V., Pelon, J., and Boone, A.: The 713 March 2006 dust storm over West Africa: generation, transport, and vertical stratification, J. Geophys. Res., 113, D00C08, doi:10.1029/2008JD009871, 2008. 